\title{
VARIABILITY OF OUTCROSSING FREQUENCY IN SENECIO VULGARIS L.
}

\author{
JOHN M. CAMPBELL* and RICHARD J. ABBOTT \\ Botany Department, University of St Andrews, St Andrews, Fife, Scotland
}

Received 31.x.75

\begin{abstract}
SUMMARY
Using a marker gene controlling capitulum type, 30 lines derived from each of a dune and a garden population of Senecio vulgaris $\mathbf{L}$. were tested for their tendency to outcross. Compared with previous estimates of outbreeding in the species a relatively high degree of outcrossing was found in both experimental populations (an overall average of 22.4 per cent). It was shown that the dune population had a slightly greater mean outcrossing frequency than the garden population but, more importantly, had significantly more heritable variation (between lines) for this trait. In discussion, some reasons are advanced to account for the unexpectedly high level of outcrossing in both populations. It is suggested that the presence of significant genetic variation for outcrossing within the dune population may provide for adaptive flexibility in the native dune habitat where there is much spatial and temporal variation of the environment.
\end{abstract}

\section{INTRODUGTION}

Groundsel, Senecio vulgaris L., has been cited as a flowering plant species which is eminently suitable for genetic studies since it combines a short generation time, rapid germination and simple growth requirements (Haskell, 1953; Harland, 1954). However, apart from early work by Trow (1912, $1916 a, b)$ the species has attracted little attention from geneticists until a recent series of studies by Hull (1974a, b, 1975), Richards (1975) and Abbott $(1976 a, b)$. In the literature, $S$. vulgaris is reported to be predominantly self-pollinated (Haskell, 1953; Fryxell, 1957) and Gibbs, Milne and VargasCarrillo (1975) have recently shown that it is a species which combines an ability to set seed by autogamy with several other features associated with well-established inbreeders, e.g. inconspicuous capitula, low pollen yield and a high recombination index. Based on limited data, Trow (1912) estimated outcrossing within the species to be usually 1 per cent in natural situations though this value may reach 10 per cent. More recently Hull (1974a) investigated the level of outcrossing in numerous wild populations located in Central Scotland and, in support of Trow, concluded that outcrossing rarely exceeded 1 per cent though frequencies of up to 10 per cent and indeed 15 per cent were computed for some populations. Variations in degree of outcrossing between populations of a predominantly selfed species are not unusual and may be under environmental and genetic control (Imam and Allard, 1965; Heslop-Harrison, 1966; Jain, Marshall and Wu, 1970). It is also clear that in some species disparate genotypes may differ greatly in outcrossing frequency when subjected to the same pollination environments (Breese, 1959; Drayner, 1959; Harding and Tucker, 1964; Horovitz and

\footnotetext{
* Present address: Department of Genetics, University of Birmingham, P.O. Box 363, Birmingham, England.
} 
Harding, 1972). Here we report an investigation where the primary aim was to establish whether $S$. vulgaris possesses a genetically variable mating system.

\section{METHOD}

Thirty randomly sampled individuals from each of a sand dune (Aberffraw, N. Wales) and a garden (Oxford) population (see Abbott, $1976 a$, for details) were tested for their tendency to outcross. Before testing for outcrossing, individuals were selfed for four generations and thus may be regarded as highly inbred lines. Estimation of outcrossing was based on the inheritance of a major gene that controls the presence or absence of ray florets. The tested populations consisted of "rayless" individuals which produce capitula without ray florets. Presence or absence of ray florets is determined by a single gene that shows incomplete dominance (Trow, 1912; Hull, 1974a). Thus when the homozygous recessive "rayless" individuals ( $r r)$ cross with homozygous dominant " rayed " types $(R R)$, mid-rayed $(R r)$ progeny are easily identified.

Two progeny of each inbred line were raised individually under glass in $6 \mathrm{~cm}$ square pots containing compost. On 26th July 1973, 50 days from sowing, plants were placed out on an experimental plot at the University Botanic Garden, St Andrews. The experiment was laid out as two replicate fully randomised blocks in which each of the 30 inbred lines from each population was represented once. Plants were spaced at $1.5 \mathrm{~m}$ intervals and there was a distance of $3 \mathrm{~m}$ between the blocks. Each rayless inbred line in both blocks was then closely $(6 \mathrm{~cm})$ surrounded by four progeny of a "rayed" pure line $(R R)$ which had been bred from an individual ( $S$. vulgaris forma radiatus Hegi) collected from waste land in Newcastle-under-Lyme, England. Up to the point of planting out rayed plants had similarly been raised under glass in $6 \mathrm{~cm}$ square pots after being sown out at the same time as the rayless individuals. Both rayed and rayless plants flowered at approximately the same time during August 1973.

Over the month of September, five open-pollinated capitula were collected from each test plant $(r r)$ and all the seed from each capitulum was subsequently sown, under glass, in mid-December. The progeny came into flower during March and April 1974 and were scored for the presence or absence of mid-ray florets.

\section{Results}

Outcrossing frequencies are expressed as the percentage of the total progeny bearing ' $m i d$ '-rays $(R r)$. In the analyses presented here only those lines are included which produced progeny in both plots and where a minimum of 10 progeny was scored, i.e. 21 lines from the garden population and 26 from the dune population.

The mean outcrossing frequency for each population together with the level expressed in each block is given in table 1 . In contrast with what might be expected a relatively high degree of outcrossing is consistently shown by both populations in both blocks (an overall average of 22.4 per cent). Analysis by means of a three-dimensional contingency $\chi^{2}$ test (table 2) (see Grawford-Sidebotham, 1970) shows that the dune population has a signifi- 
cantly higher outcrossing level than the garden population. However, it should be noted that the difference between populations is small and moreover the population $\times$ block interaction is highly significant. There was no significant difference between blocks suggesting that pollination vector activity was approximately the same throughout the experimental area.

Turning to the variation within populations the range of outcrossing values for lines in the dune population was $0-85$ per cent while in the garden population it narrowed to $9-40$ per cent. When for each individual in both

\section{TABLE 1}

Levels of outcrossing within blocks and populations

\begin{tabular}{|c|c|c|c|c|}
\hline \multirow[b]{2}{*}{ Blocks } & \multicolumn{2}{|c|}{ Population } & \multicolumn{2}{|c|}{ Both populations } \\
\hline & Dune & Garden & & \\
\hline 1 & $\begin{array}{l}25 \cdot 6 \% \\
(1,257)\end{array}$ & $\begin{array}{l}18 \cdot 6 \% \\
(748)\end{array}$ & & $\begin{array}{l}23.0 \% \\
(2005)\end{array}$ \\
\hline 2 & $\begin{array}{l}21 \cdot 1 \% \\
(1116)\end{array}$ & $\begin{array}{l}22 \cdot 6 \% \\
(967)\end{array}$ & & $\begin{array}{l}21 \cdot 8 \% \\
(2083)\end{array}$ \\
\hline Both blocks & $\begin{array}{l}23.5 \% \\
(2373)\end{array}$ & $\begin{array}{l}20.9 \% \\
(1715)\end{array}$ & Total & $\begin{array}{l}22 \cdot 4 \% \\
(4088)\end{array}$ \\
\hline
\end{tabular}

N.B. - Numbers in brackets represent the progeny scored.

populations the frequency of outcrossing in block I is plotted against performance in block 2 (fig. 1, a and b) it is seen that there is a good correlation between the performance of the dune lines in the two replicate blocks but not for lines of the garden population. This suggests that there are heritable differences in outcrossing potential between lines of the dune population, but in the garden population there is little genetic variation for the trait.

TABLe 2

The analysis of variation of the proportion of mid-rayed plants $(\mathbf{R r})$ in the progeny of different blocks and populations. The method used is based on a three-dimensional contingency $\chi^{2}$ table

\begin{tabular}{lccc}
\multicolumn{1}{c}{ Source } & d.f. & $\chi^{2}$ & $P$ \\
Blocks & 1 & $0 \cdot 8$ & N.S. \\
Populations & 1 & $4 \cdot 0$ & $5 \%-1 \%$ \\
Population $\times$ Blocks & 1 & $9 \cdot 8$ & $1 \%-0 \cdot 1 \%$
\end{tabular}

In order that the observed variation within each population may be partitioned into genetic and environmental components an analysis of variance has been carried out on the data after transforming it from percentages into angles (table 3 ).

It becomes clear that there are significant genetic differences for outcrossing between lines of the dune population, but not between those of the garden population. If it is assumed that the tested lines in each population are true-breeding it is possible to calculate an estimate of narrow heritability 


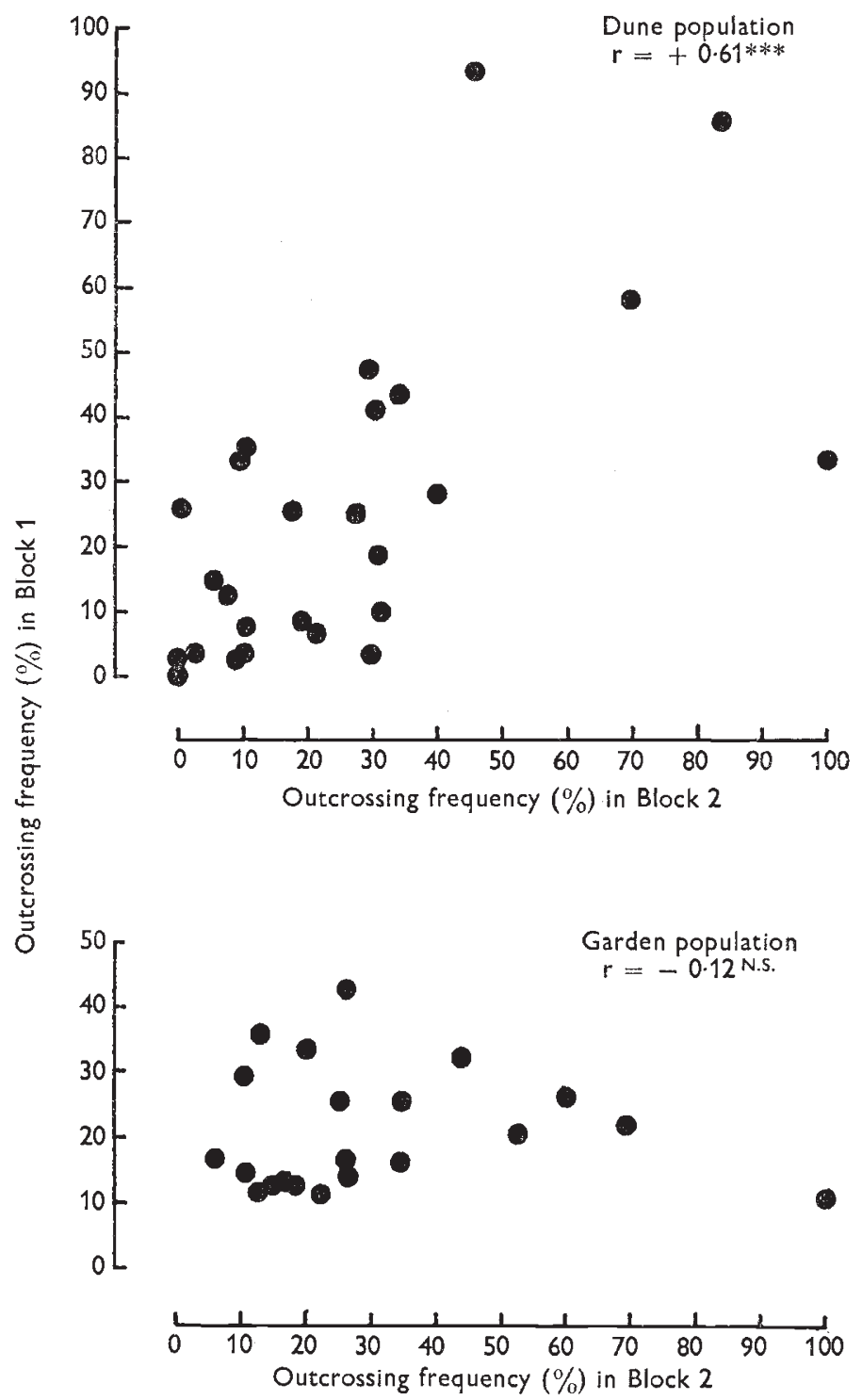

FIg. 1.-The frequency of outcrossing (per cent) for individuals of the dune and garden populations in Block 1 plotted against their respective frequencies in Block 2. Correlation coefficients $(r)$ were calculated after transforming percentages to angles.

for outcrossing in each population after estimating the variance components from the expected mean squares. After Mather and Jinks (1971);

$$
\text { Narrow heritability } \begin{aligned}
\left(h^{2}\right) & =\frac{\text { additive genetic variance }}{\text { total variance }} \\
& =\frac{\frac{1}{2} D}{\frac{1}{2} D+\frac{1}{4} H+E}
\end{aligned}
$$


Where for inbred lines

$$
\begin{aligned}
D & =V p-E \\
& =\sigma_{l}^{2} \\
& =\text { total variation (parental) - environmental variation }
\end{aligned}
$$

(error variation)

(see Mather and Jinks, 1971, p. 253).

Thus assuming there are no heterozygotes

$$
h^{2}=\frac{\frac{1}{2} D}{\frac{1}{2} D+E}=\frac{\frac{1}{2} \sigma_{l}^{2}}{\frac{1}{2} \sigma_{l}^{2}+\left[\sigma_{w}^{2}+\sigma_{i}^{2}\right]}
$$

The narrow heritability of the dune population was estimated as 42.95 per cent, indicating an appreciable amount of genetic variation in the original population. In contrast the heritability of the garden population was 0.00 per cent, which suggests that all of the variation between lines of this population is environmental in origin. A comparison of the "lines $x$ block" mean squares for the two populations showed that there was no significant difference between the environmental components of variation in the two populations $\left(\frac{174}{146}, F=1 \cdot 192\right.$, N.S.). Thus the greater heterogeneity of performance observed between lines in the dune population must be attributed to additive genetic variation which is absent in the garden population.

\section{Discussion}

Compared with previous estimates of outcrossing within $S$. vulgaris (Trow, 1912; Hull, 1974a) the mean values of our experimental populations are high. Trow's estimate was based on progeny tests of just 1 rayed $(R R)$ and 1 rayless $(r r)$ plant found growing at close proximity in a garden, while Hull's value was derived indirectly (with numerous assumptions) from the frequencies of the $R R, R r$ and $r r$ phenotypes in wild populations. Moreover, when Hull examined the progeny of three $R R$ and three $r r$ individuals sampled from two populations for which he had computed respective outcrossing values of 10 per cent and 15 per cent, he found no evidence that the parent plants had engaged in any outcrossing. It is possible, therefore, that the values of Trow and Hull may not accurately reflect the usual level of outcrossing within $S$. vulgaris.

Equally, it can be agreed that our estimates, derived from experimental populations may not represent the situation in the wild. Indeed, there are several reasons why our experimental methods may have directly inflated the usual levels of outcrossing in natural populations. First, the field studies were conducted at a time of year when insects that may act as pollinating vectors (see Haskell, 1953) were plentiful and, in contrast with Hull (1974a) we observed that rayed and rayless capitula are frequently visited by a range of insects. Secondly, the presence of a large number of rayed individuals and therefore relatively "showy" capitula in the experimental area may have increased the overall amount of insect activity and consequently boosted the usual outcrossing level. Thirdly, rayless and rayed plants were placed within groups at a high density, while on dunes and in gardens plants, in 
flower, may be more sparsely distributed. Levin and Kerster (1974) have pointed out that in low-density populations there may be a reduction in the number of pollinator visits per flower and thus more self-pollination. Finally the fact that plants were tested for outcrossing out of their natural habitats and thus subjected to a very different environmental regime could have induced a marked distortion of their normal breeding behaviour (HeslopHarrison, 1966).

Apart from the experimental methods, the history of the plants used in this study also warrants consideration. The tested rayless individuals were descendants of plants originally sampled from two populations that may be somewhat unusual in that they could be long established (see Abbott, 1976a). Within such populations it is possible that genes allowing some outcrossing,

TABLE 3

Analyses of variance of data within populations and the mean square expectation

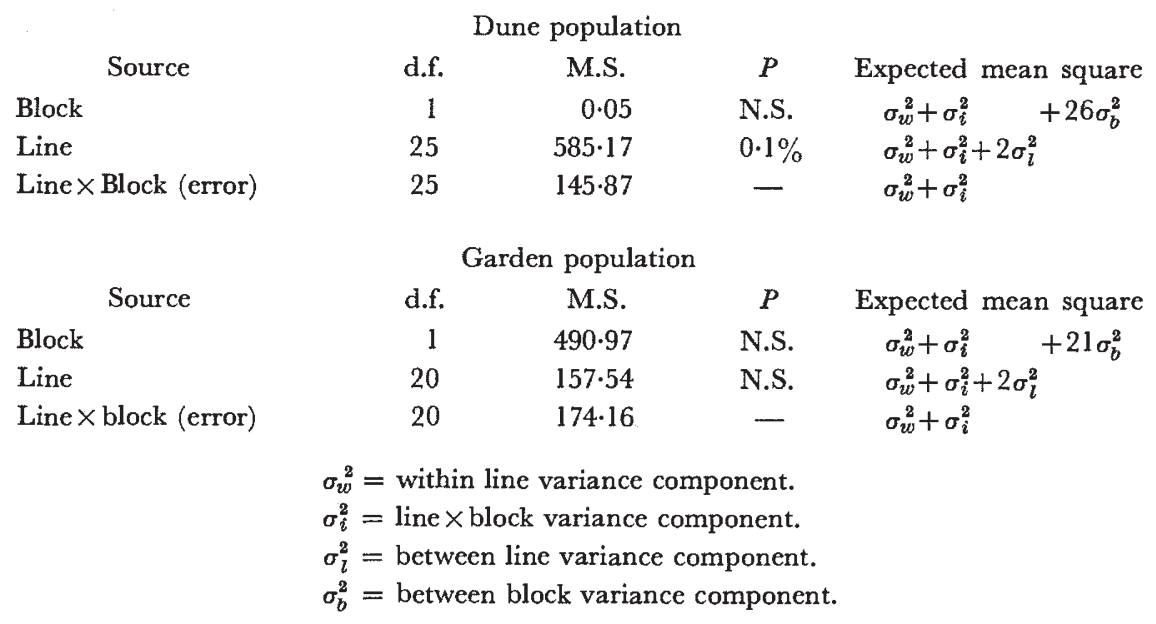

to provide for evolutionary flexibility, are at some advantage (see Kahler, Clegg and Allard, 1975). By contrast, within newly formed populations, which may be the more common type in a noted colonising species such as groundsel, a high level of selfing remains at a premium (Stebbins, 1957; Antonovics, 1968). Taking account of each of these points there could be legitimate doubts as to whether our estimates of outcrossing are representative of the levels which occur in natural situations. Nevertheless, one point has been established: our results clearly show that under appropriate conditions a significant amount of outcrossing can occur between plants of the species.

A further point of interest was the presence of significant additive genetic variance for outcrossing (not observed in the garden population) within the dune population. It is conceivable that the character we have studied may show a significant interaction between genotype and environment so that individual performance under experimental conditions is not a reliable guide of relative performance in the native sites. However, if what has been found accurately reflects the situation in the natural habitats, then we may attempt to explain the variance difference between populations as either the result of 
chance or the action of natural selection. Abbott (1976a) has reported that on the dunes there are notable variations of the spatial environment and plants grow in both exposed and sheltered micro-habitats. By contrast an enclosed garden site is relatively sheltered throughout. Adaptation to the spatial heterogeneity of the dunes appears to be highly localised (Abbott, loc. cit.), different genotypes being favoured in different micro-environments. Abbott $(1976 b)$ has suggested that with this situation a high level of selfpollination may be of great value to an ephemeral as a means of maintaining the local adaptations. However, combined with variations of the spatial environment on dunes, there are likely to be temporal variations both between and within generations. The dune habitat is noted for change with shifting sand and frequent "blow-outs". In these conditions there may be a need for genetic flexibility and thus the optimal hybridity of a population (in the sense of Darlington and Mather, 1949) may be greater than that which is achieved through almost total self-pollination. One way by which hybridity could be raised, without seriously disrupting the continuance of highly localised forms would be the presence in the population of some individuals which show a high level of outcrossing. Thus on dunes, where for reasons already stated the overall level of outcrossing within $S$. vulgaris may be much lower than was found in the present study, the optimal hybridity might be maintained by the presence of some plants that function largely as outcrossers amidst a population mainly comprised of predominantly selfpollinated individuals.

Acknowledgments. - We greatly appreciate the interest shown by Dr Brian Barnes (Birmingham) and Dr Allan Gordon (St Andrews) and their advice on statistical analyses. One of us, J. M. C., gratefully acknowledges the support of a Carnegie Undergraduate Vacation Scholarship during part of this work.

\section{REFERENCES}

Аввотт, R. J. 1976a. Variation within Common Groundsel, Senecio vulgaris L.I. Genetic response to spatial variations of the environment. New Phytol., 76, 153-164.

Аввотт, R. J. 1976b. Variation within Common Groundsel, Senecio vulgaris L.II. Local differences within cliff populations on Puffin Island. New Phytol., 76, 165-172.

ANTonovics, J. 1968. Evolution in closely adjacent plant populations. V. Evolution of self-fertility. Heredity, 23, 219-238.

BREESE, E. L. 1959. Selection for differing of out-breeding in Nicotiana rustica. Ann. Bot. N.S. $23,331-334$.

CRAWFORD-SIDEBOTHAM, T. J. 1970. Differential susceptibility of species of slugs to metaldehyde bran and to methiocarb baits. Oecologia (Berl.), 5, 303-324.

Darlington, c. D., AND Mather, x. 1949. The Elements of Genetics. George Allen and Unwin Ltd., London.

DRAYNER, J. K. 1959. Self- and cross-fertility in field beans. (Vicia Faba L.). F. Agri. Sci., $53,387-403$.

FRYXELL, P. A. 1957. Modes of reproduction in higher plants. Bot. Rev., 23, 135-233.

GibBs, P. E., Milne, C., AND VARGAs-CARrillo, м. 1975. Correlations between the breeding system and recombination index in five species of Senecio. New Phytol., 75, 619-626.

HARDING, F., AND TUCKER, C. L. 1964. Quantitative studies on mating systems. 1. Evidence for the non-randomness of outcrossing in Phaseolus Iunatus. Heredity, 19, 369-381.

HARLAND, s. G. 1954. The genus Senecio as a subject for cytogenetical investigations. Proc. Bot. Soc. Brit. Is., 1, 256.

HASkell, G. 1953. Adaptation and the breeding system in Groundsel. Genetica, 26, 468484.

HESLOP-HARRISON, J. 1966. Reflections on the role of environmentally governed reproductive versatility in the adaptation of plant populations. Trans. Bot. Soc. Edin., 40, 159-168. 
HOROVITZ, A., AND HARDING, J. 1972. The concept of male outcrossing in hermaphrodite higher plants. Heredity, 29, 223-236.

HULl, P. 1974a. Self-fertilisation and the distribution of the radiate form of Senecio-vulgaris L. in Central Scotland. Watsonia, 10, 69-75.

HULl, P. 1974b. Differences in esterase distribution detected by electrophoresis as evidence of continuing interspecific hybridisation in the genus Senecio. Ann. Bot. N.S., 38, 697-700.

HULL, P. 1975. Selection and hybridisation as possible causes of changes in the frequency of alleles controlling capitulum-type in Senecio vulgaris L. Watsonia, 10, 395-402.

IMAM, A. G., AND ALlard, R. w. 1965. Population studies in predominately self-pollinated species. VI. Genetic variability between and within natural populations of wild oats, Avena fatua L., from differing habitats in California. Genetics, 51, 49-62.

JAIN, s. K., MARShALl, D. R., AND WU, K. 1970. Genetic variability in natural populations of softchess (Bromus mollis L.). Evolution, 24, 649-659.

KAHLER, A. L., CLEGG, M. T., AND ALlARD, R. W. 1975. Evolutionary changes in the mating system of an experimental population of barley. Proc. natn. Acad. Sci. U.S.A., 72, 943-946.

Levin, D. A., AND Kerster, H. W. 1974. Gene flow in seed plants. Evol. Biol., 7, 139-220. MAther, K., AND JINks, J. K. 1971. Biometrical Genetics, 2nd Ed. Chapman and Hall, London.

RICHARDS, A. J. 1975. The inheritance and behaviour of the rayed gene complex in Senecio vulgaris. Heredity, 34, 95-104.

stebbins, G. L. 1957. Self-fertilisation and population variability in the higher plants. Am. Nat., 91, 337-354.

TROW, A. H. 1912. On the inheritance of certain characters in the common groundsel, Senecio vulgaris L., and its segregates. F. Genet., 2, 239-276.

TROW, A. H. 1916a. On the number of nodes and their distribution along the main axis of S. vulgaris and its segregates. $\mathcal{f}$. Genet., 2, 1-64.

TROW, A. H. 1916b. On "Albinism" in groundseI. F. Genet., 6, 65-74. 